\title{
White Coat Hypertension, relationship of stages of hypertension with end organ damage and diurnal variation of blood pressure in newly diagnosed hypertensive patients
}

Navaraj Paudel, ${ }^{a *}$ Prahlad Karki, ${ }^{\mathrm{b}}$ Nikesh Raj Shrestha, ${ }^{\text {b }}$ Sanjib Kumar Sharma ${ }^{\mathrm{c}}$

${ }^{a}$ Department of Internal Medicine (Nephrology Unit), College of Medical Sciences, Bharatpur, Nepal

${ }^{b}$ Department of Internal Medicine, BPKIHS, Dharan, Nepal

${ }^{c}$ Department of Internal Medicine (Cardiology Unit), College of Medical Sciences, Bharatpur, Nepal

\begin{abstract}
Accepted on

June 10th, 2012

DOI Name

10.3126/jaim.v1i2.6504

Keywords

albumin creatinine ratio, blood pressure variability, end organ damage, white coat hypertension

\section{Citation}

Paudel N, Karki P, Shrestha NR, et al. White Coat Hypertension, Relationship of stages of hypertension with end organ damage and Diurnal Variation of blood pressure in newly diagnosed Hypertensive Patients. Journal of Advances in Internal Medicine 2012;01(02):56-9.

Introduction - Systemic hypertension is a disease attributable for various cardiovascular events. White coat hypertension is under diagnosed in Nepal and is usually treated as hypertension. However its prevalence in Nepal is not known. The relationship of stages of hypertension and diurnal variation of blood pressure with end organ damage is a current topic of research however such studies haven't been done in Nepal.

Methods - A Cross-sectional, Descriptive study including 80 patients was conducted over a period of 1 year from February 2008 to March 2010 at B. P. Koirala Institute of Health Sciences (BPKIHS), Dharan.

Results - The prevalence of white coat hypertension was 9\%. Considering stage one (JNC 7) patients only it was $17 \%$. There was statistically significant association between rise in blood pressure and proteinuria ( $p=<0.001$ ). There was also significant relationship between the ECG and Fundoscopic changes with the rise in blood pressure ( $p$ value 0.003 and 0.041 respectively). There were $47 \%$ nondippers, $44 \%$ dippers, $8 \%$ extreme dippers and $1 \%$ raisers with significant variations between active and resting blood pressure.

Conclusion - The prevalence of White Coat Hypertension among stage one hypertensives was $17 \%$. There is strong relationship between the rise in blood pressure and end organ damage. Majority of patients with pre-hypertension (JNC 7) showed micro-albuminuria. There was a significant variation between active and resting blood pressure.
\end{abstract}

\section{INTRODUCTION}

Hypertension is the most important cardiovascular risk factor worldwide contributing to one half of the coronary heart disease and almost two third burdens of the cerebro-vascular disease. ${ }^{1}$ Twenty six percent (95\% $\mathrm{Cl} 26 \cdot 0-26 \cdot 8 \%)$ of the adult population in 2000 had hypertension (26.6\% of men [26.0-27.2\%] and $26 \cdot 1 \%$ of women [25.5-26.6\%]), and $29 \cdot 2 \%$ $(28 \cdot 8-29 \cdot 7 \%)$ were projected to have this condition by 2025 (29.0\% of men [28.6-29.4\%] and $29 \cdot 5 \%$ of women [29.1-29.9\%]). ${ }^{2}$ The reported prevalence of hypertension varied around the world, with the lowest prevalence in rural India ( $3.4 \%$ in men and $6.8 \%$ in women) and the highest prevalence in Poland (68.9\% in men and $72.5 \%$ in women). ${ }^{3}$ In Nepal, overall prevalence of hypertension in and around Kathmandu valley in 2008 was $19.7 \%$ ( $22.2 \%$ in men and $17.3 \%$ in women) and prevalence in age group of above 40 years was $36 \%{ }^{4}$ The community prevalence of hypertension in Nepalese community in Eastern Nepal was found to be $27 \%$ in the year $2006 .^{5}$

Assessing white coat hypertension (WCH) is an important consideration in newly diagnosed hypertensive patients as it does not require immediate pharmacotherapy but frequent monitoring of BP is indicated as it sometimes predates hypertension. ${ }^{1}$ The prevalence of $\mathrm{WCH}$ ranges from $5-7 \%$ to $40-45 \%$ with average being $15-20 \%$ in the stage one hypertensive patients around the world, ${ }^{1}$ but the prevalence of $\mathrm{WCH}$ in Nepal is not known. There is an association of rise of blood pressure with end organ damages; in form of increase in left ventricular mass, arteriolar stiffening and thickening and damage to the endothelium leading to retinopathy and nephropathy. ${ }^{6}$ However association of rise of blood pressure with end organ damages has not been adequately studied in Nepal.
According to the American Heart Association, an excessive morning blood pressure surge is a predictor of stroke in elderly people with hypertension. ${ }^{7}$ Patients with diminished night time fall in BP (non-dippers) have been proposed as a subgroup of patients associated with an increased frequency of damage to all End organs (brain, heart, and kidney) and higher frequency of cardiovascular events compared to patients with normal dipping. ${ }^{7,8}$ Despite of the emerging clinical importance of Diurnal variation of BP; it has not been studied adequately in Nepalese population till now.

\section{METHODS}

A Cross-sectional, descriptive study was conducted from February 2008 to March 2010 at B. P. Koirala Institute of Health Sciences (BPKIHS), Dharan. Inclusion criteria were the patients above 15 years attending the OPD and diagnosed as hypertension (who had blood pressure SBP $>140 \mathrm{mmHg}$ or DBP $>90 \mathrm{~mm} \mathrm{Hg}$ ). Initial Screening of BP measurement would be the standard auscultatory method with a random zero mercury sphygmomanometer and standard cuff $(12 \times 34 \mathrm{~cm})$. BP was measured in seated position quietly in a chair with foot on the floor and arm supported at the heart level. SBP was the point where the first 1 or more sounds heard after releasing the properly inflated cuff and DBP was the point of disappearance of sounds. Two measurements were taken in five minutes apart and mean of two were taken. The same was repeated in the other arm. The reading showing higher level in any arm was taken as the blood pressure of that individual. Those patients who had the blood pressure $>140 / 90 \mathrm{mmHg}$;

\footnotetext{
* Corresponding author

Navaraj Paudel,

Department of Internal Medicine, College of Medical Sciences, Bharatpur, Nepal.

Email address - drnavarajmd@gmail.com
} 
were put on Ambulatory Blood Pressure Monitoring tool and readings were taken after 24 hours. Patients who were in urgent need of antihypertensive e.g. Hypertensive emergency/ urgency, acute medico-surgical conditions (fever, known UTI, acute colic etc.) or not giving consent and on anti-hypertensive agents were excluded. Patients with known renal, cardiac diseases were also excluded. With the prevalence of hypertension in the community being around $27 \%$ in Nepal and $\mathrm{WCH}$ among the hypertensives in the world being around $15-20 \%$, we calculated the number required to study using $4 \mathrm{pq} / \mathrm{L2}$. Taking the allowable error of $5 \%$, the number required was around 76 . Patients who met the inclusion criteria were selected and an informed written consent was taken. They were put on the 24hour ABPM tool from 9:00 am and the recordings were taken after 24 hours (9:00 am; the day after). A patient was suspected to have WCH when the BP was $140 / 90 \mathrm{mmHg}$ or above in three separate readings in hospital settings with two or more normal readings outside the hospital setting without evidence of end organ damage i.e. (no nephropathy/ micro-albuminuria, no evidence of hypertensive retinopathy, or no evidence of hypertensive heart disease as explained by no evidence of ECG changes). The patients would be considered as hypertensive in 24 hour ABPM if active/day-time Systolic BP/diastolic BP $>135 / 85 \mathrm{mmHg}$ and Resting/night-time systolic $B P /$ diastolic $B P>120 / 75 \mathrm{mmHg}$. This corresponds to $>140 / 90 \mathrm{mmHg}$ in conventional method of BP measurement. The patient would be called as extreme dippers, dippers, non-dippers or raisers if there was nocturnal fall in BP by more than $20 \%, 10$ to $20 \%, 0-10 \%$ or less than $0 \%$ respectively. ABPM was done by SCHILLER BR-102+ tool available in the hospital and conventional blood pressure measuring was done by the standard mercury Sphygmomanometer with standard cuff that had been calibrated weekly. Data collected were analyzed using SPSS software. Chi-square test was done for analyzing the white coat hypertension, individual relationship between the rise of blood pressure and variables as proteinuria, ECG changes and fundoscopic changes secondary to Hypertension. Independent sample t test was used to assess the difference in means between active and resting mean arterial pressure, systolic blood pressure and diastolic blood pressure.

\section{RESULTS}

The total number of patients taken for the study were 80 , although consent for the study was taken of 90 patients, 10 were excluded from the study because 9 did not have total 24 hours figures of blood pressure recordings and 1 did not have the reports of urinary ACR .

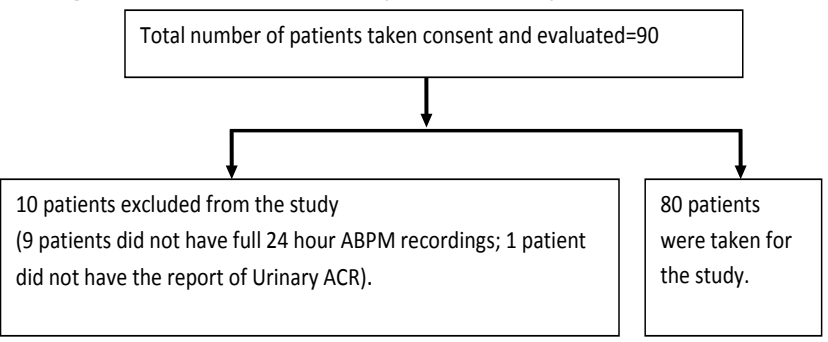

The male patients studied were $43(54 \%)$ and the female were $37(46 \%)$. Most of the patients studied were in the age group of $15-45$ years $(n=42)$ followed by $46-65$ years $(n=32$ ). Two of the patients were detected to have diabetes and 50 had positive family history of hypertension. Maximum number of people (47) were overweight according to body mass index. Forty three had waist to hip ratio more than one. 24 hour ABPM showed that only $48(60 \%)$ met criteria for hypertension on 24 hour monitoring but further evaluation of end organ damage demonstrated evidence of hypertensive changes in end organs except in 7 (9\%) of patient. These cases accounted for $\mathrm{WCH}$.
Table 1. White coat hypertension in patients with JNC 7 stage $1 \& 2$ hypertension.

\begin{tabular}{llllll} 
Variables & $\begin{array}{l}\text { No of } \\
\text { patients } \\
\text { tested }\end{array}$ & $\begin{array}{l}\text { positive } \\
\text { resutls }\end{array}$ & $\begin{array}{l}\text { negative } \\
\text { results }\end{array}$ & $\begin{array}{l}\text { patients } \\
\text { tested -ve in } \\
\text { all variables }\end{array}$ & $\%$ \\
\hline 24 hour ABPM & 80 & $48(60 \%)$ & $32(40 \%)$ & 7 & 9 \\
24 hr urinary protein & 80 & $50(62 \%)$ & $30(38 \%)$ & \\
& 80 & $70(88 \%)$ & $10(12 \%)$ & \\
$\begin{array}{l}\text { Urine for ACR } \\
\text { ECG }\end{array}$ & 80 & $30(38 \%)$ & $50(62 \%)$ & \\
$\begin{array}{l}\text { Fundoscopic } \\
\text { changes in retina due }\end{array}$ & 80 & $16(29 \%)$ & $64(80 \%)$ & \\
to hypertension & & &
\end{tabular}

According to the case definition explained earlier, the cumulative prevalence in $\mathrm{WCH}$ in the study population was shown to be $9 \%$. This included the entire stage one and stage two (JNC-7) hypertensive patients that were enrolled in this study (Table 1 ). In further analysis taking only the stage one subgroups the prevalence of the WCH was found to be $17 \%$ (Table 2), reflecting that patients with higher recordings according to conventional method tend to have true hypertension.

Spot urinary albumin creatinine ratio (ACR) was performed and was calculated as $\mathrm{mg} / \mathrm{gm}$, and $65 \%$ of the people in the study had micro-albuminuria; $22 \%$ had overt proteinuria and only $12 \%$ had normal results. Only $71 \%$ of those having abnormal ACR showed abnormal proteinuria according to 24 hour urine collection method to assess proteinuria. The statistical tests were performed to further analyze the relationship between the rise in blood pressure and end organ damage. The urinary ACR shows that there is significant relationship ( $p<0.001$ ) (table 3 ). It also showed significant relationship between the ECG and fundus changes with the rise in blood pressure ( $p$ value 0.003 and 0.041 respectively) (table 4). The diurnal variation was also assessed in these patients that showed $47 \%$ non-dippers, $44 \%$ dippers, $8 \%$ extreme dippers and $1 \%$ raisers where total of $53 \%$ of the study population had abnormal diurnal rhythm of blood pressures. There was statistically significant difference between resting and active mean arterial pressure, systolic blood pressure and diastolic blood pressure using independent sample t-test as shown in table 5 . The magnitude of difference in means (mean difference $=7.95 ; 95 \% \mathrm{Cl}=4.55,11.34$ ) was moderate (eta squared $=0.11$ ) for mean arterial pressure. Similarly for systolic blood pressure (mean difference $=10.52 ; 95 \% \mathrm{Cl}=6.37,14.67$ ) and diastolic blood pressure (mean difference $=6.09 ; 95 \% \mathrm{Cl}=2.85,9.31$ ) the difference in mean was moderate (eta squared $=0.13$ and 0.08 respectively).

\section{DISCUSSION}

Systemic hypertension is the major disease burden all over the world taking many lives secondary to its vascular events with significant mortality and morbidity. 
Table 2. Measurement to show white coat hypertension (only taken as stage 1 hypertension of the office blood pressure recordings by calibrated sphygmomanometer).

\begin{tabular}{llllll} 
Variables & $\begin{array}{l}\text { No of } \\
\text { patients } \\
\text { tested }\end{array}$ & $\begin{array}{l}\text { positive } \\
\text { resutls }\end{array}$ & $\begin{array}{l}\text { negative } \\
\text { results }\end{array}$ & $\begin{array}{l}\text { patients } \\
\text { tested -ve in } \\
\text { all variables }\end{array}$ & $\%$ \\
\hline 24 hour ABPM & 52 & $22(42 \%)$ & $30(58 \%)$ & 9 & 17 \\
24 hr urinary protein & 52 & $22(42 \%)$ & $30(58 \%)$ & \\
$\begin{array}{l}\text { Urine for ACR } \\
\text { ECG }\end{array}$ & 52 & $42(81 \%)$ & $10(19 \%)$ & \\
& 52 & $4(8 \%)$ & $48(92 \%)$ & \\
$\begin{array}{l}\text { Fundoscopic } \\
\text { changes in retina due } \\
\text { to hypertension }\end{array}$ & 52 & $2(4 \%)$ & $50(96 \%)$ & \\
\end{tabular}

Older patients had a higher prevalence of $\mathrm{WCH}$ with a higher prevalence of among patients with lower clinic systolic BP and diabetic patients. ${ }^{8,9}$ The prevalence of $\mathrm{WCH}$ in the patients in our study showed $7(9 \%)$ which included all the patients of stage one and stage two hypertension according to JNC-7. This figure was too low than the other studies where only stage one hypertensive groups were studied. Thus the patients having WCH in stage one hypertension (52 patients) were further evaluated and the prevalence of $\mathrm{WCH}$ in this subgroup was $9(17 \%)$. This figure was comparable to the studies done outside. ${ }^{1}$

In normal individuals the average difference between waking and sleeping systolic and diastolic pressure is $10-20 \%{ }^{10}$ Although the night time $B P$ in 24 hour ABPM to call the persons having hypertension is low $(>120 / 75 \mathrm{mmHg}$ ), we had found that there were significant number of people (53\%) with abnormal results. It could be because the studied people were too anxious and also were not given any anti-anxiety drugs. Anxiety increases blood pressure, often by as much as $30 \mathrm{mmHg}$ or more in different individuals. ${ }^{8}$

Independent studies have shown that for subject with blunted or abolished fall dip and abnormal ABP result in higher incidences of LV hypertrophy and CV mortality. ${ }^{8}$ Excessive morning blood pressure surge is a predictor of stroke in elderly people with high blood pressure. ${ }^{7}$ These variations are associated with an increased frequency of damage to all End organs (brain, heart, and kidney) and worse prognosis for cardiovascular events when compared with patients with normal dipping. ${ }^{11}$ In our study also there was significant variability in the blood pressure recordings between the active/ day time period and the resting/ night time period.

The individual relationship between the rise of blood pressure and the end organ damage was also studied that showed a significant relationship between them. Urinary ACR was $30 \%, 94 \%$ and $100 \%$ in patients having mean blood pressure of $<115 / 75 \mathrm{mmHg},>115-134 / 75-84 \mathrm{mmHg}$ and $>135 / 85 \mathrm{mmHg}$ respectively. Albuminuria (proteinuria) is considered an independent risk factor for cardiovascular events. ${ }^{12}$ Reduction of albumi-
Table 3. Relation between blood pressure rise and proteinuria (chi square test)

Variable

$\begin{array}{lll}24 \text { hr Blood } & \text { Normal Abnormal p-value } \\ \text { pressure }(\mathrm{mmHg}) & & \end{array}$

\begin{tabular}{|c|c|c|c|c|}
\hline \multirow[t]{3}{*}{ Urine for ACR } & $<115 / 75$ & 7 & 3 & $<0.001$ \\
\hline & $115-134 / 75-84$ & 3 & 49 & \\
\hline & $>135 / 85$ & 0 & 18 & \\
\hline
\end{tabular}

Table 4. Showing relation between BP rise with Fundoscopic and ECG changes (chi square test)

Variable

$\begin{array}{lll}24 \mathrm{hr} \text { Blood } & \text { Normal Abnormal p-value } \\ \text { pressure }(\mathrm{mmHg}) & & \end{array}$

\begin{tabular}{lllll}
\hline Fundoscopy changes & $<115 / 75$ & 0 & 10 & 0.003 \\
& $115-134 / 75-84$ & 0 & 47 & \\
& $>135 / 85$ & 16 & 7 & \\
ECG changed & $<115 / 75$ & 0 & 10 & 0.041 \\
& & & & \\
& $115-134 / 75-84$ & 0 & 42 & \\
& $>135 / 85$ & 28 & 0
\end{tabular}

nuria reduces cardiovascular events in hypertensive patients. ${ }^{13}$

Our study also shows significant association of high blood pressure with left ventricular hypertrophy. Hypertension causes various effects in heart affecting both the diastolic and systolic function. ${ }^{14} \mathrm{~A}$ large meta-analysis is done to show effect of hypertension in heart and decrease in cardiovascular events by reduction of left ventricular mass in hypertension. ${ }^{15}$

This study has also shown the significant association of rise of blood pressure with hypertensive retinopathy. Studies have shown that routine fundoscopic evaluation helps to diagnose and prognosticate chronic hypertension as well as monitoring of the effectiveness of the treatment. ${ }^{16}$

As with any study this current study also has its own limitations which we discuss further. The low prevalence of white coat hypertension in the total number of patient studied is because both stage 1 and stage 2 hypertensives were included in the study as mentioned earlier. Proteinuria was found in higher than expected number of subjects. Factors influencing proteinuria as fever, drugs, known renal diseases, acute medico-surgical conditions etc. had been excluded but independent renal diseases (not secondary to hypertension) could not be excluded because of lack of resources which might have confounded the results. In this study the voltage criteria in ECG were taken for evaluation of LVH where Echocardiography would have been a better option. 
Table 5. Showing statistically significant difference between resting and active mean arterial pressure, systolic blood pressure and diastolic blood pressure using independent sample t-test

\begin{tabular}{lcccc} 
Variables & t-value & df & p-value & $\mathbf{9 5 \%}$ CI \\
\hline Mean arterial pressure (MAP) & 4.62 & 147.62 & $<0.001$ & $4.55,11.33$ \\
Systolic blood pressure (SBP) & 5.00 & 151.83 & $<0.001$ & $6.37,14.67$ \\
& & & & \\
Diastolic blood pressure (DBP) & 3.72 & 158 & $<0.001$ & $2.85,9.31$
\end{tabular}

\section{REFERENCES}

1. Kotchen AT. Hypertensive Vascular Disease. In: Fauci AS, Braunwald E, Kasper D, et al, ed. Harrison's principles of Internal Medicine. Volume 2. 17th ed. McGraw-Hill; 2008: 1553.

2. Kearney PM, Whelton M, Reynolds K, et al. Global burden of hypertension: analysis of worldwide data. Lancet 2005;365:21723.

3. Kearney PM, Whelton M, Reynolds K, et al. Worldwide prevalence of hypertension: a systematic review. J Hypertens 2004;22:11-9.

4. Shrestha B, Dhungel S. Ambulatory blood pressure monitoring a useful tool in diagnosing hypertension and monitor the treatment. Nepal Med Coll J 2008;10:118-22.

5. Codreanu I, Perico N, Sharma SK, et al. Prevention programmes of progressive renal disease in developing nations. Nephrology (Carlton) 2006;11:321-8.

6. Agabiti-Rosei E, Muiesan ML, Salvetti M: Evaluation of subclinical target organ damage for risk assessment and treatment in the hypertensive patients: left ventricular hypertrophy. J Am Soc Nephrol 2006;17:104-8.

7. Gosse $\mathrm{P}$, Lasserre $\mathrm{R}$, Minifrè $\mathrm{C}$, et al. Blood pressure surge on rising. J Hypertens 2004;22:1113-18.

8. Lurbe E, Redon J, Kesani A, et al. Increase in nocturnal blood pressure and progression to microalbuminuria in type 1 diabetes. N Engl J Med 2002;347:797-805

\section{CONCLUSION}

The prevalence of $\mathrm{WCH}$ among stage one hypertensives was $9(17 \%)$. There was strong relationship between the rise in blood pressure and end organ damage. Majority of patients with pre-hypertension (JNC 7) showed micro-albuminuria; so it is conceivable that the end organ damage begins in the pre-hypertensive stage itself. Routine screening of microalbuminuria starting from the stage of prehypertension is recommended. This might have important effect on treatment consideration thus requires validation by further larger studies designed to overcome the limitations of this current study. The blood pressure variability was seen as $47 \%$ nondippers, $44 \%$ dippers, $8 \%$ extreme dippers and $1 \%$ raisers with statistical significant variations in active and resting $B P$.

9. Helvaci MR, Seyhanli M. What a high prevalence of white coat hypertension in society! Intern Med 2006;45:671-4.

10. Pickering TG, Harshfield GA, Kleinert HD, et al. Blood pressure during normal activities, sleep, and exercise: comparison of values in normal and hypertensive subjects. JAMA 1982;247;992-6.

11. Parati G, Frattola A, Di Rienzo M, et al. Blood Pressure Variability. Importance in Research and in Clinical Hypertension. Arq Bras Cardiol 1996;67:131-3.

12. Schmieder RE, Schrader J, Zidek W, et al. Subclinical albuminuria, microalbuminuria and proteinuria-accepted cardiovascular risk markers? Dtsch Med Wochenschr 2006;131:2665-71.

13. Ibsen $\mathrm{H}$, Olsen $\mathrm{MH}$, Wachtell $\mathrm{K}$, et al. Reduction in albuminuria translates to reduction in cardiovascular events in hypertensive patients: Losartan intervention for endpoint reduction in hypertension study. Hypertension 2005;45:198-202.

14. Schmieder RE, Messerli FH: Hypertension and the heart J Hum Hypertens 2000;14:597-604.

15. Verdecchia P, Angeli F, Borgioni C, et al. Changes in cardiovascular risk by reduction of left ventricular mass in hypertension: a meta-analysis. Am J Hypertens 2003;16:895-9.

16. van den Born BJ, Hulsman CA, Hoekstra JB, et al. Value of routine funduscopy in patients with hypertension: systematic review. BMJ 2005;331:73 